\title{
Dietary patterns, food groups and myocardial infarction: a case-control study
}

\author{
Michael S. K. Lockheart ${ }^{1}$, Lyn M. Steffen ${ }^{1}$, Hege Møklebust Rebnord ${ }^{2}$, Ragnhild Lekven Fimreite $^{2}$, \\ Jetmund Ringstad $^{3}$, Dag S. Thelle ${ }^{4}$, Jan I. Pedersen ${ }^{2}$ and David R. Jacobs Jr ${ }^{1,2} *$ \\ ${ }^{1}$ Division of Epidemiology and Community Health, School of Public Health, University of Minnesota, 1300 South 2nd Street, \\ Suite 300, Minneapolis, MN 55454, USA \\ ${ }^{2}$ Department of Nutrition, University of Oslo, Oslo, Norway \\ ${ }^{3}$ Department of Infectious Diseases, Østfold Central Hospital, Fredrikstad, Norway \\ ${ }^{4}$ Sahlgrenska University Hospital in Gothenberg, Gothenberg, Sweden
}

(Received 18 July 2006 - Revised 26 January 2007 - Accepted 31 January 2007)

\begin{abstract}
Certain dietary patterns may be related to the risk of CVD. We hypothesised that a plant-centred dietary pattern would be associated with a reduced risk of first myocardial infarction (MI). A case-control study of Norwegian men and postmenopausal women (age 45-75 years) was performed. A FFQ was administered, generally within $3 \mathrm{~d}$ after incident MI ( $n$ 106 cases). Controls ( $n$ 105) were frequency matched on sex, age and geographic location. On the FFQ, 190 items were categorised into thirty-five food groups and an a priori healthy diet pattern score was created. We estimated OR using logistic regression with adjustment for energy intake, family history of heart disease, marital status, current smoking, education and age. Among food groups, the risk of MI was significantly higher per SD of butter and margarine (OR 1.66 (95\% CI 1.12, 2.46)), and lower per SD of tomatoes (OR 0.53 (95\% CI 0.35, 0.79)), high-fat fish (OR 0.57 (95\% CI 0.38, 0.86)), wine (OR 0.58 (95\% CI 0.41, 0.83)), salad (OR 0.59 (95\% CI 0.40, 0.87)), wholegrain breakfast cereals (OR 0.64 (95\% CI 0.45, 0.90)), cruciferous vegetables (OR 0.66 (95\% CI 0.47, 0.93)) and non-hydrogenated vegetable oil (OR $0.68(95 \%$ CI $0.49,0.95)$ ). An abundance of cases were found to have a low a priori healthy diet pattern score. A dietary pattern emphasising nutrient-rich plant foods and high-fat fish and low in trans fatty acids was associated with decreased risk of MI among Norwegians.
\end{abstract}

Dietary patterns: Myocardial infarction: Western diet: Prudent diet: Plant-based diet: Vegetarian diet: Whole grains

CHD may be largely preventable through optimisation of dietary intake, in addition to maintaining a healthy weight, regular exercise and avoiding tobacco ( $\mathrm{Hu} \&$ Willett, 2002). Investigations of the role of diet in chronic disease have increasingly focused on the role of overall dietary intake (Hu, 2002; Kris-Etherton et al. 2002; Newby \& Tucker, 2004). Dietary patterns, defined as multiple dietary components operationalised as a single exposure (Kant, 2004; Schulze \& Hoffmann, 2006), may be derived from existing data (a posteriori) using factor or cluster analysis, describing actual patterns of dietary intake captured by FFQ. Alternatively, adherence to dietary patterns defined $a$ priori may be measured with dietary indices. Defining dietary patterns a priori allows for testing of putative optimal dietary patterns, such as the Alternate Healthy Eating Index (McCullough et al. 2002; McCullough \& Willett, 2006), which are not necessarily derived using a posteriori methods. Both approaches have been used to study the role of diet in $\mathrm{CHD}$, generally finding that a prudent dietary pattern is associated with a reduced risk of CHD (Hu et al. 2000; Fung et al. 2001) and total mortality (Osler et al. 2001).
Studying overall diet as an exposure, rather than individual dietary components such as nutrients or foods, offers advantages including the ability to identify significant cumulative effects which may be too small to detect with isolated dietary components. Interactions among nutrients also contribute to associations detected by dietary pattern analysis, allowing the study of food synergy without specific knowledge of the myriad interactions among known and unknown components of foods (Jacobs \& Murtaugh, 2000; Messina et al. 2001; Jacobs \& Steffen, 2003). Modelling overall diet further allows for greater ease in translating research findings into dietary recommendations.

Few studies have examined dietary patterns in Norway. A recent investigation (Engeset et al. 2005) of over 37000 Norwegian women described several dietary clusters, including two that approximated the prudent and Western patterns found in other populations ( $\mathrm{Hu}$ et al. 2000; Fung et al. 2001). The European Prospective Investigation into Cancer and Nutrition (EPIC) investigators (Engeset et al. 2005) described regional differences, with the 'healthy' and 'alcohol drinkers' clusters more highly represented in southeast Norway, the region where cases and controls were recruited

\footnotetext{
Abbreviations: MI, myocardial infarction.

* Corresponding author: Dr David R. Jacobs Jr, fax +1612624 0315, email jacobs@epi.umn.edu
} 
for the present study. They also found a 'fish eaters' pattern, as well as a 'bread eaters' pattern, the latter being particularly rich in coarse bread, though coarse bread intake was far greater in every cluster compared with refined white bread. Whole grains are more commonly eaten than refined grains in Norway, where, according to Food Disappearance data, four times as much whole grain is consumed compared with the USA (Jacobs et al. 2001). An investigation of nearly 17000 Norwegian men and women found that higher wholegrain consumption was associated with reduced mortality, despite that some wholegrain foods are consumed by most Norwegians (Jacobs et al. 2001).

Our aim in the present investigation was to describe dietary patterns and their association with first myocardial infarction (MI) in a Norwegian case-control study. We first compared risk of MI as determined by food groups alone $v$. a dietary pattern derived from the same food groups using an a priori healthy diet score. Because our work has shown trans fatty acids to be higher in adipose tissue from cases $v$. controls (Pedersen et al. 2000), we anticipated that margarine consumption, the major source of trans fatty acids at the time of study, would be associated with higher risk.

\section{Subjects and methods}

\section{Design and subjects}

In this case-control study of first MI (Pedersen et al. 2000; Yli-Jama et al. 2001, 2002; Biong et al. 2006), 111 cases and 107 controls were recruited during 1995 to 1997 . Due to missing data, 106 cases and 105 controls were analysed. Study subjects were native Norwegian men and postmenopausal women between the ages of 45 and 75 years, with no history of previously reported MI or other serious disease (including cancer, diabetes, drug abuse or major psychiatric illness) which may have influenced their dietary intake. Subjects using hypolipidaemic drugs or oestrogen replacement therapy, or with changes in body weight of more than $5 \mathrm{~kg}$ during the previous year were excluded from the study. Informed consent was obtained for all participants in accordance with the ethical standards set by the committees on human experimentation. Among those asked to participate, $5 \%$ refused.

Cases were diagnosed with a first MI (International Classification of Diseases (ICD)-9 code 410 with typical history, electrocardiographic and enzyme changes) and admitted within $24 \mathrm{~h}$ of symptom onset to the coronary care units of Ullevål University Hospital in Oslo or either of the Ostfold Central Hospitals in Fredrikstad and Sarpsborg. Two cases had angina before MI, but stated that they had not made dietary changes. Interviews generally occurred within $3 \mathrm{~d}$ of admission, except in a few cases in which interviewing was delayed until up to 1 week post-admission.

Controls were recruited from the catchment areas of the case hospitals, and frequency matched to correspond to cases for sex, age (5-year intervals) and geographic location; angina pectoris cases were excluded from the control group. As it was thought that population-based samples would result in low response rates that would compromise internal validity, controls were recruited from friends and relatives of the cases, state and municipal employees (excluding doctors and nurses), individuals attending recreation centres for the elderly and retired, and members of associations such as Rotary and Lions Club or church groups. Towards the end of the study, friends and relatives of collaborators were also accepted as controls. This resulted in some controls with higher education. Findings with seventy-seven cases and 102 controls who had at most 16 years of education were similar to those presented here and are not shown. An effort was made to recruit each control within 2 months of the MI event of the corresponding case in order to minimise seasonal variation in reported dietary intake.

\section{Dietary assessment}

Dietary intake during the previous 1 year was assessed using a standardised and validated FFQ developed at the Department of Nutrition, University of Oslo (Oslo, Norway). The FFQ was completed during a 90 min interview with each study participant. During interviews with the male patients their spouses or cohabitants were invited to participate. This FFQ had previously been tested in two validation studies, which compared the FFQ with $14 \mathrm{~d}$ of weighed diet records and found median nutrient correlations of 0.51 in a study of 125 Norwegian men of median age 38 (Andersen et al. 1999), and 0.70 in a study of thirty-one Norwegian women of median age 71 (Nes et al. 1992).

The 190 individual food items captured by the FFQ were grouped together in thirty-five non-overlapping food groups consisting of related food items (Table 1). These food groups were defined using grouping criteria similar to those described for other studies of dietary patterns ( $\mathrm{Hu}$ et al. 2000; Fung et al. 2001; Kerver et al. 2003). Food items were combined into food groups based on similarities such as nutrient content, culinary usage and hypothesised contribution to diet-disease relationships. It should be noted that several single FFQ items (wine, liquor, chicken, salad, nuts, pizza) stand on their own as food groups because no other food items captured by the FFQ were deemed appropriate for combination with these foods into multiple-item food groups. Total energy intake was calculated from FFQ data using the official Norwegian food composition table (National Nutrition Council, 1995).

\section{Derivation of the a priori healthy diet score}

We previously created an a priori diet score by summing rankings of six food groups; high scores corresponded to a healthy diet, i.e. low intake of meat and high intake of each of whole grain, fruit, vegetable, nut, and dairy foods (Steffen et al. 2005). In prediction of incident elevated blood pressure in young adults, the relative hazard for quintile 5 of this score was 0.59 (95\% CI 0.45, 0.76) (Steffen et al. 2005). Elaborating this score in the present study, an a priori healthy diet pattern score was defined as a sum of tertile rankings over twenty-eight of the food groups for which a hypothesis was made that the food group would be generally protective against or would be generally causative of MI. We postulated that results from this score would be similar to those in other studies of dietary patterns and CHD, namely that nutrient-rich plant foods and fish, as they are part of prudent patterns $(\mathrm{Hu}$ et al. 2000; Fung et al. 2001; Kant, 2004; Schulze \& 
Table 1. Definitions of food groups in terms of food frequency questionnaire items

\begin{tabular}{|c|c|}
\hline Food group & FFQ items contributing to food group* \\
\hline Cheese and yogurt & Yogurt, light yogurt, white cheese (3), brown cheese (2) \\
\hline Low-fat dairy & Low-fat milk, skimmed milk, light sour cream \\
\hline High-fat milk & $\begin{array}{l}\text { Milk, whole milk, sweet whole milk, high-fat cream, cream, sour cream (2), } \\
\text { ice cream, cream desserts, pudding }\end{array}$ \\
\hline Butter and margarine $\dagger$ & $\begin{array}{l}\text { Butter or margarine unspecified (2), butter (2), Smoregod, Bremykt, Brelett, } \\
\text { margarine (2), margarine blend (2), soya margarine (3), vegetable margarine, soft light margarine }\end{array}$ \\
\hline Low-energy drinks & Diet soda, diet fruit drinks, water, mineral water \\
\hline High-energy drinks & Sugar soda, sugar fruit drinks, alcohol-free beer \\
\hline Coffee & Brewed coffee, instant coffee, filtered coffee \\
\hline Tea & Black tea, herbal tea \\
\hline Wine & Wine \\
\hline Beer & Light beer, regular beer, strong beer \\
\hline Liquor & Liquor \\
\hline Eggs & Eggs, whole eggs \\
\hline Fruit & Bananas, apples, fruit spreads, other fruit, citrus fruit, berries, fruit cocktail \\
\hline Fruit juice & Orange juice, other juice \\
\hline Wholegrain breads & Heavy wholegrain breads, dark flat breads, medium wheat breads \\
\hline Wholegrain breakfast cereals & Rolled oats, four-grain cereal, corn and oat flakes, muesli \\
\hline Refined grains & $\begin{array}{l}\text { Refined wheat flour, parboiled rice, polished rice, spaghetti, white breads, hot dog buns and } \\
\text { potato cakes, refined light flatbreads, white school bread, Vienna bread, waffles (3), sweet yeast breads }\end{array}$ \\
\hline Low-fat fish & $\begin{array}{l}\text { White fish, pollack, flounder, freshwater fish, lean fish, fried cod, minced fish products, shrimp } \\
\text { and crab, crab sticks, fish soup }\end{array}$ \\
\hline High-fat fish & $\begin{array}{l}\text { Herring, spring mackerel, fall mackerel, salmon and trout, fish liver, smoked salmon and trout, } \\
\text { pickled herring, mackerel sandwich topping, sardine and herring topping, caviar, fish oil, cod oil }\end{array}$ \\
\hline Chicken & Chicken \\
\hline Liver & Liver, lean liver pâté, regular liver pâté \\
\hline Red and processed meats & $\begin{array}{l}\text { Pork and beef cutlets, bacon, salt-dried cold cuts, smoked sausage, veal sausage, pork sausage, } \\
\text { hot dogs (3), blood pudding, meat toppings, fried meat, meat stew, chopped meat stew, steak, } \\
\text { lamb, meat casserole, hamburger, game }\end{array}$ \\
\hline Non-hydrogenated vegetable oil & Vegetable cooking oil, soya and maize oil, olive oil \\
\hline Dressings, mayonnaise and sauces & $\begin{array}{l}\text { Regular dressings, light dressings, Italian dressings, light Italian dressings, mayonnaise (2), light } \\
\text { mayonnaise, brown sauce, Béarnaise sauce, white sauce }\end{array}$ \\
\hline Cruciferous vegetables & Cauliflower, cabbage, sweet and sour cabbage \\
\hline Tomatoes & Raw tomatoes, canned tomatoes \\
\hline Salad & Salad \\
\hline Other vegetables & $\begin{array}{l}\text { Carrots, rutabaga, onions, cucumbers, red peppers, vegetable toppings, boiled vegetables, mixed } \\
\text { vegetables (5) }\end{array}$ \\
\hline Condiments & $\begin{array}{l}\text { Pickles, mustard, ketchup, artificial sweeteners, light jams, regular jams, granulated sugar, sugar } \\
\text { cubes, honey, sweet toppings }\end{array}$ \\
\hline Chips and snacks & Potato chips (crisps), other snacks \\
\hline Nuts & Nuts \\
\hline Potatoes & Potatoes, boiled potatoes, mashed potatoes, fried potatoes, French fries \\
\hline Pizza & Pizza \\
\hline Soup & Vegetable beef stew, clear soup, powdered soup, pea soup \\
\hline Sweets & Cookies, doughnuts, nutcakes, filled cakes, chocolate, chocolate candy, other sweets \\
\hline
\end{tabular}

* The number of FFQ questions contributing to a listed food item is indicated in parentheses; for example, the FFQ had three questions about white cheese indicated by (3) and two questions about brown cheese indicated by (2).

$\dagger$ At the time of the study most margarines contained partially hydrogenated fat (vegetable and marine oils).

Hoffmann, 2006), would emerge as related to reduced MI risk, while red meats and nutrient-poor plant foods, typical of Western patterns (Hu et al. 2000; Fung et al. 2001; Kant, 2004; Schulze \& Hoffmann, 2006), would emerge as associated with higher risk. Food groups considered to be generally protective were cheese and yogurt, low-fat dairy (Pereira et al. 2002; Steffen et al. 2005), tea (Hertog et al. 1993; Peters et al. 2001, 2002), wine, beer, liquor (Mukamal et al. 2006), fruit (Liu et al. 2000; Steffen et al. 2003, 2005), wholegrain breads, wholegrain breakfast cereals (Jacobs et al. 1998), low-fat fish, high-fat fish (Steffen et al. 2005), chicken (Ghosh et al. 2003), non-hydrogenated vegetable oil (Mensink \& Katan, 1989; Estruch et al. 2006), dressings, mayonnaise, and sauces (Mensink \& Katan, 1989), cruciferous vegetables, tomatoes, salad, other vegetables (Liu et al. 2000; Steffen et al.
2003, 2005), nuts (Mensink \& Katan, 1989; Ghosh et al. 2003; Jiang et al. 2006), and soup (often high in vegetable or fish content in Norway). Eight food groups were hypothesised to contribute to MI risk: high-fat milk (Anderson et al. 1979; Steffen \& Jacobs, 2003), butter and margarine (Pedersen et al. 2000), high-energy drinks (Schulze et al. 2004), liver (organ meats are particularly high in cholesterol), red and processed meats (Steffen et al. 2005), chips and snacks, sweets, and pizza (foods commonly eaten in obesogenic diets). Not included in the pattern were foods for which hypotheses were ambiguous or which were thought not to be relevant to MI risk: low-energy drinks (Davidson \& Swithers, 2004), eggs (Nakamura et al. 2006; Qureshi et al. 2006), fruit juice (beneficial nutrients may be counteracted by high energy content), coffee (Greenland, 1993; Andersen et al. 2006), refined 
grains (Jacobs et al. 1998; Steffen et al. 2003), condiments (small absolute intake might counteract high sugar and salt content), and potatoes (beneficial nutrients may be counteracted by preparation method or high starch content).

\section{Statistical analysis}

All statistical analyses were conducted using SAS software (version 9.1; SAS Institute, Cary, NC, USA). In thirty-five separate multivariate logistic regression analyses we examined OR for MI in thirty-five food groups, each represented as a continuous natural logarithmic transformation of $\mathrm{g} / \mathrm{d}$ intake, in SD units. In addition, we carried out parallel logistic regression analyses with each food group in three categories determined from tertile cut-off points of intake $(\mathrm{g} / \mathrm{d})$ within the control group and reported the OR for MI between the highest and lowest intake categories. Because sample size was relatively small, we analysed only one food group or one dietary pattern score in each regression analysis. Covariates in all regression analyses were family history of heart disease in first-degree relatives (yes $v$. no), current marital or cohabitant status (yes $v$. no), current smoking (yes $v$. no), education (four categories), energy intake $(\mathrm{kJ} / \mathrm{d})$ and age (years). Note that sex and geographic location were addressed by frequency matching controls to cases. Controls were also frequency matched for age (5-year intervals), and continuous age was also included in our regression model to address the possibility of residual confounding by age. To compute the a priori healthy diet pattern score we summed tertile rankings over the twenty-eight food groups for which a hypothesis about direction of risk was made. First, tertiles of intake, using $\mathrm{g} / \mathrm{d}$ cut-off points derived from the control group, were assigned values 0 for the lowest, 1 for the middle and 2 for the highest for the twenty food groups assumed to relate inversely to MI. Tertile coding was reversed (2 for the lowest, 1 for the middle and 0 for the highest) for the eight food groups hypothesised to contribute to MI risk. Note that foods are added into the score based on their ranks in the control sample distribution, rather than based on $\mathrm{g}$ weight consumed. Distribution of the healthy diet pattern score was considered for cases and controls and logistic regression with the above covariates was used to estimate the OR of MI in categories of the score.

\section{Results}

Case ( $n$ 106) and control ( $n$ 105) participants were of similar age $(62.5$ (SD 7.7) years in cases and 62.2 (SD 7.7) years in controls), marital status (73 v. $74 \%$ married) and energy intake (9741 (SD 3077) v. 9742 (SD 2903) kJ/d). Cases had higher levels of current smoking (59 v. 19\%), family history of CHD (64 v. 42\%) and waist:hip ratio (0.95 (SD 0.08) v. 0.90 (SD 0.08)); fewer cases had education past high school (24 v. $51 \%$ ). As previously reported (Pedersen et al. 2000; Yli-Jama et al. 2002), cases and controls had similar mean BMI, but cases had higher waist:hip ratio, TAG and history of antihypertensive drug use, but lower levels of HDL-cholesterol and total cholesterol, the latter presumed to represent an acute-phase response (Pedersen et al. 2000).

Risk of MI was consistently reduced (Table 2) for the following nutrient-rich plant food groups: tomatoes (OR continuous model $0 \cdot 53$, OR highest intake category $0 \cdot 38$ ), salad (OR continuous model $0 \cdot 59$, OR highest intake category $0 \cdot 34$ ) and wholegrain breakfast cereals (OR continuous model 0.64, OR highest intake category $0 \cdot 38$ ). Cruciferous vegetable intake was also greater in controls, but significantly so only in the continuous model. Intake of other vegetables was nearly significant in both models in the expected direction. Tea intake was higher in controls, though not significant in either model.

Wine was significant in both models (OR continuous model $0 \cdot 58$, OR highest intake category $0 \cdot 27$ ). Beer and liquor lacked statistical significance in their associations with MI but there was a trend toward greater intake in controls. A non-significant reduction was seen for total alcohol intake (data not shown). Few individuals indicated heavy drinking; the median alcohol intake in the highest tertile indicated less than two $15 \mathrm{~g}$ drinks/d.

'Butter and margarine' was significantly positively associated with the risk of MI in both models (OR continuous model 1.66, OR highest intake category 2.80); in contrast, both non-hydrogenated vegetable oil and high-fat fish intake were greater in controls. High-fat fish included supplemental cod-liver oil, which was consumed by $42 \%$ of the sample; relative risk of MI was 1.90 (95\% CI $0.95,3.80)$ in nonusers compared with users. Liver was positively associated with MI in both models but did not reach statistical significance.

For several food groups OR were in an unexpected direction. High-fat dairy intake was greater in the controls, significantly so in the categorical model. Cheese and yogurt (both fermented foods high in fat at the time of study) intake was nearly significantly higher in controls in both models. Intake of both pizza and sweets was non-significantly greater in controls. Non-significant associations were detected for all other food groups in both models.

A strong and inverse association was observed between the a priori healthy diet pattern score and risk of MI. Table 3 describes the shape of the association. There were almost no controls with scores $<18$. In scores of 18 and above, risk was more gradually graded, such that there were relatively few cases for scores of 28 and above. Adjusted OR compared with the lowest category were below $0 \cdot 25$, generally decreasing as the score increased. Because the lowest category was small in number, we also examined risk for those with a score of $<25$, the two lowest categories pooled. Adjusted OR compared with this reference group were 0.5 or less for each higher category. $P$ for trend was 0.004 if the healthy diet pattern was represented as a linear variable. The significant differences observed between the a priori score categories $11-17$ and 18-24, as well as between the categories 11-24 and 25-27, and the apparent flattening of the association across higher categories are consistent with the possibility that the shape of the risk curve is non-linear. We considered that the association might be mediated by body fatness. Further adjustment for waist:hip ratio attenuated the association of the healthy diet pattern with MI ( $P$ for trend $=0.03$ ).

\section{Discussion}

Our findings in analyses of both dietary patterns and individual food groups were consistent with our hypothesis 
Table 2. Food group distribution and risk for first myocardial infarction from two multiple logistic regression models for each food group, one with the food group represented as a continuous variable, the other with the food group represented in three categories $†$

(Odds ratios and $95 \%$ confidence intervals)

\begin{tabular}{|c|c|c|c|c|c|c|c|c|}
\hline \multirow[b]{3}{*}{ Food group } & \multicolumn{3}{|c|}{ Continuous food group model } & \multicolumn{5}{|c|}{ Categorical food group model } \\
\hline & \multirow[b]{2}{*}{ SD $\ddagger$} & \multicolumn{2}{|c|}{$\begin{array}{l}\text { Risk per SD of In food } \\
\text { group intake }(\mathrm{g} / \mathrm{d})\end{array}$} & \multicolumn{3}{|c|}{$\begin{array}{l}\text { Control group category } \\
\text { median }(\mathrm{g} / \mathrm{d})\end{array}$} & \multicolumn{2}{|c|}{$\begin{array}{l}\text { Risk for highest } \\
v . \text { lowest intake }\end{array}$} \\
\hline & & OR & $95 \% \mathrm{Cl}$ & 1 & 2 & 3 & OR & $95 \% \mathrm{Cl}$ \\
\hline Cheese and yogurt & 1 & 0.69 & $0.47,1.01$ & 25 & 47 & 98 & 0.42 & $0.18,1.03$ \\
\hline Low-fat dairy & $1 \cdot 3$ & 0.93 & $0.66,1.32$ & 48 & 223 & 618 & 0.96 & $0.42,2.23$ \\
\hline High-fat milk & 1.5 & 0.82 & $0.58,1.16$ & 8 & 36 & 118 & 0.48 & $0.20,1.14$ \\
\hline Butter and margarine & 0.8 & $1 \cdot 66^{*}$ & $1 \cdot 12,2 \cdot 46$ & 7 & 14 & 36 & $2 \cdot 80^{\star}$ & $1 \cdot 14,6 \cdot 85$ \\
\hline Low-energy drinks & 1.5 & 0.84 & $0.60,1.17$ & 140 & 334 & 747 & $1 \cdot 01$ & $0.45,2.29$ \\
\hline High-energy drinks & $2 \cdot 1$ & 1.07 & $0.76,1.52$ & 0 & 51 & 189 & $1 \cdot 10$ & $0.48,2.55$ \\
\hline Coffee & $1 \cdot 7$ & $1 \cdot 11$ & $0.77,1.59$ & 120 & 420 & 900 & 1.90 & $0.80,4.51$ \\
\hline Tea & $2 \cdot 4$ & $0 \cdot 80$ & $0.58,1.12$ & 0 & 50 & 400 & 0.62 & $0.26,1.47$ \\
\hline Wine & $1 \cdot 8$ & $0.58^{*}$ & $0.41,0.83$ & 0 & 16 & 86 & $0 \cdot 27^{*}$ & $0.11,0.68$ \\
\hline Beer & $2 \cdot 2$ & 0.83 & $0.59,1.16$ & 0 & 40 & 140 & 0.70 & $0.32,1.55$ \\
\hline Liquor & $1 \cdot 3$ & 0.81 & $0.58,1 \cdot 13$ & 0 & 3 & 14 & 0.52 & $0.22,1.19$ \\
\hline Eggs & 0.7 & 1.07 & $0.76,1.52$ & 6 & 16 & 29 & 0.80 & $0.35,1.82$ \\
\hline Fruit & 1 & 0.76 & $0.54,1.09$ & 51 & 123 & 216 & 0.69 & $0.30,1.58$ \\
\hline Fruit juice & $2 \cdot 1$ & 0.97 & $0.69,1.36$ & 0 & 12 & 140 & 0.83 & $0.37,1.87$ \\
\hline Wholegrain breads & 0.8 & 0.94 & $0.67,1.32$ & 94 & 164 & 240 & 0.89 & $0.35,2.26$ \\
\hline Wholegrain breakfast cereals & 1.5 & $0.64^{*}$ & $0.45,0.90$ & 0 & 8 & 36 & $0 \cdot 38^{*}$ & $0.16,0.92$ \\
\hline Refined grains & 0.8 & 0.90 & $0.63,1.30$ & 21 & 41 & 84 & 1.41 & $0.59,3.37$ \\
\hline Low-fat fish & 0.7 & 0.90 & $0.63,1.28$ & 32 & 65 & 99 & $0 \cdot 70$ & $0.31,1.59$ \\
\hline High-fat fish & 0.9 & $0.57^{*}$ & $0.38,0.86$ & 12 & 28 & 52 & 0.54 & $0.23,1.26$ \\
\hline Chicken & $1 \cdot 1$ & 1.02 & $0.73,1.43$ & 1 & 6 & 16 & $1 \cdot 14$ & $0.51,2.52$ \\
\hline Liver & 1 & 1.39 & $0.99,1.97$ & 0 & 2 & 11 & 1.99 & $0.87,4.57$ \\
\hline Red and processed meats & 0.5 & 0.86 & $0.56,1.32$ & 52 & 93 & 143 & 0.65 & $0.25,1.70$ \\
\hline Non-hydrogenated vegetable oil & 0.4 & $0 \cdot 68^{*}$ & $0.49,0.95$ & 0 & 0.3 & $1 \cdot 3$ & 0.53 & $0.24,1.18$ \\
\hline Dressings, mayonnaise and sauces & 0.9 & $1 \cdot 16$ & $0.80,1.68$ & 2 & 9 & 20 & 1.06 & $0.45,2.50$ \\
\hline Cruciferous vegetables & $1 \cdot 2$ & $0.66^{*}$ & $0.47,0.93$ & 2 & 8 & 24 & 0.50 & $0.23,1.11$ \\
\hline Tomatoes & 1 & $0.53^{*}$ & $0.35,0.79$ & 1 & 5 & 15 & $0 \cdot 38^{*}$ & $0.16,0.95$ \\
\hline Salad & 0.9 & $0.59^{*}$ & $0.40,0.87$ & 0.2 & 2 & 9 & $0.34^{*}$ & $0.14,0.83$ \\
\hline Other vegetables & 0.7 & 0.77 & $0.54,1.10$ & 70 & 122 & 186 & 0.56 & $0.24,1.29$ \\
\hline Condiments & 0.9 & 0.93 & $0.66,1.33$ & 12 & 30 & 68 & 1.02 & $0.44,2.35$ \\
\hline Chips and snacks & 0.9 & 0.93 & $0.66,1.32$ & 0 & 1 & 4 & 0.62 & $0.29,1.33$ \\
\hline Nuts & $1 \cdot 1$ & $1 \cdot 24$ & $0.86,1.78$ & 0 & 1 & 4 & $1 \cdot 24$ & $0.58,2.69$ \\
\hline Potatoes & 0.7 & 0.97 & $0.67,1.41$ & 84 & 136 & 202 & 1.58 & $0.65,3.84$ \\
\hline Pizza & $1 \cdot 3$ & 0.72 & $0.50,1.04$ & 0 & 3 & 21 & 0.59 & $0.24,1.48$ \\
\hline Soup & $1 \cdot 1$ & 0.87 & $0 \cdot 61,1 \cdot 24$ & 3 & 13 & 30 & 0.83 & $0.35,1.95$ \\
\hline Sweets & 1 & 0.76 & $0.54,1.08$ & 7 & 21 & 38 & 0.56 & $0.24,1.29$ \\
\hline
\end{tabular}

${ }^{*} P<0.05$

†Categories were formed in SAS (version 9.1; SAS Institute, Cary, NC, USA) as tertiles determined within the control group; most contain approximately thirty-five individuals per category. OR are adjusted for age, marital status, education, family history of heart disease, smoking, and energy intake. $\ddagger S D$ of in food group intake $(\mathrm{g} / \mathrm{d})$.

that a nutrient-rich plant-centred diet is associated with a reduced risk of MI. We found significantly lower odds of MI for a higher score on an a priori formulation of a healthy diet pattern, based on the ideas of prudent and Western patterns similar to those in other studies (Hu et al. 2000; Fung et al. 2001; Kant, 2004; Schulze \& Hoffmann, 2006). Analyses of individual food groups offered further support for a protective association of nutrient-rich plant foods. Comparison of dietary pattern and food group results offered a greater understanding of overall diet, as intake of foods are consumed in patterns, so that risk associations of foods may be confounded by other foods. The strength of the association between the healthy diet pattern score and risk of MI underscores the important role of diet in this disease. It is provocative that the gradient of risk appeared to be non-linear, being large across very low values of the healthy diet pattern score, then more shallowly graded for higher values. However, the present study is rather small to make judgments about the shape of the risk function.
Our findings, together with concordant findings for risk associated with individual food groups, lend further support to the often-reported inverse association between vegetables and fruits and CHD (Hu \& Willett, 2002; Kris-Etherton et al. 2002; Srinath Reddy \& Katan, 2004). 'Wholegrain breakfast cereals' was significantly associated with reduced risk of MI, but 'wholegrain breads' was not. Consumption of wholegrain breads is common in Norway and had associations with other, less healthy, foods, while wholegrain breakfast cereal intake tended to be associated generally with the healthier pattern. These food correlations may have contributed to the difference in risk findings for wholegrain breads $v$. breakfast cereals. The evidence for a protective effect of whole grains is consistent with a previous Norwegian study in which whole-grain food intake was inversely associated with CHD and CVD death (Jacobs et al. 2001).

Most studies of alcohol and CHD risk have reported a Ushaped relationship of CHD risk with total alcohol, rather 
Table 3. Risk for first myocardial infarction according to category of the a priori diet pattern* (Odds ratios and $95 \%$ confidence intervals)

\begin{tabular}{|c|c|c|c|c|c|c|}
\hline \multirow{2}{*}{$\begin{array}{l}\text { Category of the a priori healthy } \\
\text { diet pattern score }\end{array}$} & \multirow[b]{2}{*}{ Controls $(n)$} & \multirow[b]{2}{*}{ Cases $(n)$} & \multicolumn{2}{|c|}{$\begin{array}{l}\text { Risk compared with the } \\
\text { lowest category }\end{array}$} & \multicolumn{2}{|c|}{$\begin{array}{l}\text { Risk compared with the two } \\
\text { lowest categories }\end{array}$} \\
\hline & & & OR & $95 \% \mathrm{Cl}$ & OR $\ddagger$ & $95 \% \mathrm{Cl}$ \\
\hline $11-17$ & 2 & 19 & 1.00 & & $1.00 ?$ & \\
\hline $18-24$ & 23 & 43 & 0.25 & $0.06,0.98$ & $1.00\}$ & combined \\
\hline $25-27$ & 25 & 16 & 0.13 & $0.03,0.56$ & 0.38 & $0.15,0.95$ \\
\hline $28-30$ & 25 & 14 & 0.17 & $0.04,0.73$ & 0.50 & $0.19,1.27$ \\
\hline $31-33$ & 15 & 7 & 0.10 & $0.02,0.55$ & 0.30 & $0.09,1.02$ \\
\hline $34-44$ & 15 & 7 & 0.15 & $0.03,0.72$ & 0.42 & $0.13,1.33$ \\
\hline
\end{tabular}

${ }^{\star} P$ for trend 0.004 (linear score).

† As described in the Methods, the a priori healthy diet pattern score was formed based on expert judgment of the authors, following principles of prudent and Western diet patterns. Foods were summed according to their tertile position, using cut-off points derived from the control group. A higher tertile position increased the score for cheese and yogurt, low-fat dairy, tea, wine, beer, liquor, fruit, wholegrain breads, wholegrain breakfast cereals, low-fat fish, high-fat fish, chicken, non-hydrogenated vegetable oil, dressings, mayonnaise, and sauces, cruciferous vegetables, tomatoes, salad, other vegetables, nuts, and soup. A lower tertile position increased the score for high-fat milk, butter and margarine, high-energy drinks, liver, red and processed meats, chips (crisps) and snacks, sweets, and pizza. Not included in the pattern were low-energy drinks, eggs, fruit juice, coffee, refined grains, condiments, and potatoes. The score has a theoretical range of 0-56.

$\ddagger O R$ are adjusted for age, marital status, education, family history of heart disease, smoking, and energy intake.

than a specific beverage (Hill, 2005); however, we did not find a significant association with total alcohol, as we did for wine. The question about type of alcoholic beverage notwithstanding, our findings are consistent with reports of lower risk in moderate drinkers $v$. non-drinkers (Hill, 2005). Because higher alcohol intake was rare, we had little power to assess any increase in risk at higher levels of alcohol intake.

The study findings are in agreement with an emphasis on lipid quality rather than quantity (Hu et al. 2001; Hu \& Willett, 2002; Kris-Etherton et al. 2002). While butter and margarine intake was associated with an increased risk of MI, the intake of non-hydrogenated vegetable oil, though very low, was positively associated with a prudent pattern, and inversely associated with MI in one food group model. High-fat fish, which included cod-liver oil (Brustad et al. 2004), was clearly inversely associated with MI, and as previously reported, n-3 fatty acids were higher in adipose tissue (Pedersen et al. 2000) and serum (Yli-Jama et al. 2001) from controls v. cases. Nuts, another fatty food, were too infrequently consumed to assess their association with MI risk. The finding of excess risk for butter and margarine is not part of a general excess risk for dairy foods, which had various associations with MI risk. High-fat dairy was suggestively inversely associated with MI; in addition, dairy-derived adipose tissue fatty acids have been found to be associated with a reduced risk of MI in our work (Biong et al. 2006). Cheese and yogurt intake (fermented dairy products high in fat) was non-significantly inversely associated with MI. We were unable to separate butter from margarine because several spreads were blends. Also, at the time of the study, the margarines were rich in trans fatty acids and the excess risk associated with butter and margarine intake may thus reflect a greater influence of the trans fatty acids in the margarines than of saturated fat (Pedersen et al. 2000).

There was an inverse association of MI with high-fat fish intake. In part, observed associations of fish intake with MI may be less than the true effect of fish because of the Norwegian dietary preference for fish served with melted butter and margarine.

Tea was non-significantly inversely related to MI, and loaded positively to a prudent pattern, and negatively to the
Western pattern, findings consistent with the possible protective association of tea on MI (Peters et al. 2001, 2002). Coffee was not associated with the risk of MI, in agreement with a large meta-analysis which concluded that an effect of coffee on risk of MI was unlikely (Greenland, 1993). Coffee boiled or otherwise prepared so that it retains certain fatty acids is highly cholesterol raising and may elevate the risk of MI (Thelle et al. 1983; Zock et al. 1990), although other substances in coffee may hinder other conditions (van Dam \& Hu, 2005; Andersen et al. 2006). High- and low-energy drinks showed no association with MI as food groups.

The lack of positive association of sweets with MI was unexpected. However, this food group contained food items which have been associated with reduced risk of CHD in other studies, namely nuts (Hu et al. 1998; Sabate, 1999; Kris-Etherton et al. 2001; Albert et al. 2002), including almond paste, and chocolate (Ding et al. 2006). In addition, the extraction rate for grain is higher in Norway than in other countries such as the USA, so that Norwegian refined grains resemble whole grains more closely than American refined grains.

Our findings occurred despite relatively low power. The typical SE of the regression coefficient per SD of a natural logarithmically transformed food group predicting the MI logit was $0 \cdot 18$; this implies that we had $80 \%$ power to detect a $40 \%$ decrease or a $65 \%$ increase in MI risk. Some of the non-significant findings may well have been significant if the study had been larger and therefore had a larger discriminatory power. Indeed, it is remarkable that our findings are similar to those of larger studies, despite the small number of cases and controls. There were other potential limitations. A few controls selected as a convenience sample included friends and family of study collaborators, who tended to have more resources; this led to a more highly educated control group; exclusion of the more highly educated controls did not alter estimates greatly. Recall bias may have caused an overestimate of the diet and MI association; it is possible in case-control studies that cases shade their diet report towards unfavourable foods as a personal explanation of why they got sick. On the other hand, the protocol was carefully done and there were many positive design features: efforts were made 
to reduce recall bias of dietary intake and other systematic errors; cases were interviewed as soon as possible within $3 \mathrm{~d}$ after MI; and controls was recruited so as to minimise seasonal variation in reported diet.

In conclusion, in a case-control study of diet and MI in Norwegian adults food group analyses and findings for an ad hoc but a priori healthy diet pattern score that followed principles of prudent $v$. Western diet provided further support for the conclusion that MI is inversely associated with intake of nutrient-rich plant foods and fish. Overall these data support our hypothesis that a cardioprotective diet is high in nutrientrich plant foods and fish, and low in meat products. These results are generally consistent with studies of diet and CHD in other populations ( $\mathrm{Hu}$ et al. 2000; Fung et al. 2001; Kerver et al. 2003; Kant, 2004; Schulze \& Hoffmann, 2006), including adverse influence of trans fatty acid intake, and add to the body of literature supporting the healthful effects of a nutrient-rich plant-centred diet.

\section{Acknowledgements}

The present study was supported by NIH NRSA T32HL007779, CVD Epidemiology and Prevention, American Heart Association - Greater Midwest Affiliate, Throne Holst's Foundation for Nutrition Research, The Norwegian Association of Margarine Producers, DeNoFa Fabriker A/S and Tine Norwegian Dairies.

\section{References}

Albert CM, Gaziano JM, Willett WC \& Manson JE (2002) Nut consumption and decreased risk of sudden cardiac death in the Physicians' Health Study. Arch Intern Med 162, 1382-1387.

Andersen LF, Jacobs DR Jr, Carlsen MH \& Blomhoff R (2006) Consumption of coffee is associated with reduced risk of death attributed to inflammatory and cardiovascular diseases in the Iowa Women's Health Study. Am J Clin Nutr 83, 1039-1046.

Andersen LF, Solvoll K, Johansson LR, Salminen I, Aro A \& Drevon CA (1999) Evaluation of a food frequency questionnaire with weighed records, fatty acids, and $\alpha$-tocopherol in adipose tissue and serum. Am J Epidemiol 150, 75-87.

Anderson JT, Jacobs DR Jr, Foster N, Hall Y, Moss D, Mojonnier L \& Blackburn H (1979) Scoring systems for evaluating dietary pattern effect on serum cholesterol. Prev Med 8, 525-537.

Biong AS, Veierod MB, Ringstad J, Thelle DS \& Pedersen JI (2006) Intake of milk fat, reflected in adipose tissue fatty acids and risk of myocardial infarction: a case-control study. Eur J Clin Nutr 60, 236-244.

Brustad M, Braaten T \& Lund E (2004) Predictors for cod-liver oil supplement use - the Norwegian Women and Cancer Study. Eur $J$ Clin Nutr 58, 128-136.

Davidson TL \& Swithers SE (2004) A Pavlovian approach to the problem of obesity. Int J Obes Relat Metab Disord 28, 933-935.

Ding EL, Hutfless SM, Ding X \& Girotra S (2006) Chocolate and prevention of cardiovascular disease: a systematic review. Nutr Metab (Lond) 3, 2.

Engeset D, Alsaker E, Ciampi A \& Lund E (2005) Dietary patterns and lifestyle factors in the Norwegian EPIC cohort: the Norwegian Women and Cancer (NOWAC) study. Eur J Clin Nutr 59, 675-684.

Estruch R, Martinez-Gonzalez MA, Corella D, et al. PREDIMED Study Investigators (2006) Effects of a Mediterranean-style diet on cardiovascular risk factors: a randomized trial. Ann Intern Med 145, 1-11.
Fung TT, Willett WC, Stampfer MJ, Manson JE \& Hu FB (2001) Dietary patterns and the risk of coronary heart disease in women. Arch Intern Med 161, 1857-1862.

Ghosh A, Bose K \& Das Chaudhuri AB (2003) Association of food patterns, central obesity measures and metabolic risk factors for coronary heart disease (CHD) in middle aged Bengalee Hindu men, Calcutta, India. Asia Pac J Clin Nutr 12, 166-171.

Greenland S (1993) A meta-analysis of coffee, myocardial infarction, and coronary death. Epidemiology 4, 366-374.

Hertog MG, Feskens EJ, Hollman PC, Katan MB \& Kromhout D (1993) Dietary antioxidant flavonoids and risk of coronary heart disease: the Zutphen Elderly Study. Lancet 342, 1007-1011.

Hill JA (2005) In vino veritas: alcohol and heart disease. Am J Med Sci 329, 124-135.

Hu FB (2002) Dietary pattern analysis: a new direction in nutritional epidemiology. Curr Opin Lipidol 13, 3-9.

Hu FB, Manson JE \& Willett WC (2001) Types of dietary fat and risk of coronary heart disease: a critical review. J Am Coll Nutr 20, $5-19$.

Hu FB, Rimm EB, Stampfer MJ, Ascherio A, Spiegelman D \& Willett WC (2000) Prospective study of major dietary patterns and risk of coronary heart disease in men. Am J Clin Nutr 72, 912-921.

Hu FB, Stampfer MJ, Manson JE, Rimm EB, Colditz GA, Rosner BA, Speizer FE, Hennekens CH \& Willett WC (1998) Frequent nut consumption and risk of coronary heart disease in women: prospective cohort study. BMJ 317, 1341-1345.

Hu FB \& Willett WC (2002) Optimal diets for prevention of coronary heart disease. JAMA 288, 2569-2578.

Jacobs DR, Meyer HE \& Solvoll K (2001) Reduced mortality among whole grain bread eaters in men and women in the Norwegian County Study. Eur J Clin Nutr 55, 137-143.

Jacobs DR Jr, Meyer KA, Kushi LH \& Folsom AR (1998) Wholegrain intake may reduce the risk of ischemic heart disease death in postmenopausal women: the Iowa Women's Health Study. Am $J$ Clin Nutr 68, 248-257.

Jacobs DR \& Murtaugh MA (2000) It's more than an apple a day: an appropriately processed, plant-centered dietary pattern may be good for your health. Am J Clin Nutr 72, 899-900.

Jacobs DR \& Steffen LM (2003) Nutrients, foods, and dietary patterns as exposures in research: a framework for food synergy. Am J Clin Nutr 78, Suppl., 508S-513S.

Jiang R, Jacobs DR Jr, Mayer-Davis E, Szklo M, Herrington D, Jenny NS, Kronmal R \& Barr RG (2006) Nut and seed consumption and inflammatory markers in the multi-ethnic study of atherosclerosis. Am J Epidemiol 163, 222-231.

Kant AK (2004) Dietary patterns and health outcomes. J Am Diet Assoc 104, 615-635.

Schulze MB \& Hoffmann K (2006) Methodological approaches to study dietary patterns in relation to risk of coronary heart disease and stroke. Br J Nutr 95, 860-869.

Kerver JM, Yang EJ, Bianchi L \& Song WO (2003) Dietary patterns associated with risk factors for cardiovascular disease in healthy US adults. Am J Clin Nutr 78, 1103-1110.

Kris-Etherton PM, Etherton TD, Carlson J \& Gardner C (2002) Recent discoveries in inclusive food-based approaches and dietary patterns for reduction in risk for cardiovascular disease. Curr Opin Lipidol 13, 397-407.

Kris-Etherton PM, Zhao G, Binkoski AE, Coval SM \& Etherton TD (2001) The effects of nuts on coronary heart disease risk. Nutr Rev 59, 103-111.

Liu S, Manson JE, Lee IM, Cole SR, Hennekens CH, Willett WC \& Buring JE (2000) Fruit and vegetable intake and risk of cardiovascular disease: the Women's Health Study. Am J Clin Nutr 72, 922-928.

McCullough ML, Feskanich D, Stampfer MJ, Giovannucci EL, Rimm EB, Hu FB, Spiegelman D, Hunter DJ, Colditz GA \& Willett WC (2002) Diet quality and major chronic disease risk in men and 
women: moving toward improved dietary guidance. Am J Clin Nutr 76, 1261-1271.

McCullough ML \& Willett WC (2006) Evaluating adherence to recommended diets in adults: the Alternate Healthy Eating Index. Public Health Nutr 9, 152-157.

Mensink RP \& Katan MB (1989) Effect of a diet enriched with monounsaturated or polyunsaturated fatty acids on levels of low-density and high-density lipoprotein cholesterol in healthy women and men. $N$ Engl J Med 321, 436-441.

Messina M, Lampe JW, Birt DF, Appel LJ, Pivonka E, Berry B \& Jacobs DR Jr (2001) Reductionism and the narrowing nutrition perspective: time for reevaluation and emphasis on food synergy. $J$ Am Diet Assoc 101, 1416-1419.

Mukamal KJ, Chiuve SE \& Rimm EB (2006) Alcohol consumption and risk for coronary heart disease in men with healthy lifestyles. Arch Intern Med 166, 2145-2150.

Nakamura Y, Iso H, Kita Y, Ueshima H, Okada K, Konishi M, Inoue M \& Tsugane S (2006) Egg consumption, serum total cholesterol concentrations and coronary heart disease incidence: Japan Public Health Center-based prospective study. Br J Nutr 96, 921-928.

National Nutrition Council (1995) Food Composition Table. Oslo: University Press.

Nes M, Frost Andersen L, Solvoll K, Sandstad B, Hustvedt BE, Lovo A \& Drevon CA (1992) Accuracy of a quantitative food frequency questionnaire applied in elderly Norwegian women. Eur J Clin Nutr 46, 809-821.

Newby PK \& Tucker KL (2004) Empirically derived eating patterns using factor or cluster analysis: a review. Nutr Rev 62, 177-203.

Osler M, Heitmann BL, Gerdes LU, Jorgensen LM \& Schroll M (2001) Dietary patterns and mortality in Danish men and women: a prospective observational study. Br J Nutr 85, 219-225.

Pedersen JI, Ringstad J, Almendingen K, Haugen TS, Stensvold I \& Thelle DS (2000) Adipose tissue fatty acids and risk of myocardial infarction - a case-control study. Eur J Clin Nutr 54, 618-625.

Pereira MA, Jacobs DR Jr, Van Horn L, Slattery ML, Kartashov AI \& Ludwig DS (2002) Dairy consumption, obesity, and the insulin resistance syndrome in young adults: the CARDIA Study. JAMA 287, 2081-2089.

Peters U, Poole C \& Arab L (2001) Does tea affect cardiovascular disease? A meta-analysis. Am J Epidemiol 154, 495-503.
Peters U, Poole C \& Arab L (2002) Re: Does tea affect cardiovascular disease? A meta-analysis. Erratum. Am J Epidemiol 155, 781.

Qureshi AI, Suri FK, Ahmed S, Nasar A, Divani AA \& Kirmani JF (2006) Regular egg consumption does not increase the risk of stroke and cardiovascular diseases. Med Sci Monit 13, CR1-CR8.

Sabate J (1999) Nut consumption, vegetarian diets, ischemic heart disease risk, and all-cause mortality: evidence from epidemiologic studies. Am J Clin Nutr 70, Suppl. 3, 500S-503S.

Schulze MB, Manson JE, Ludwig DS, Colditz GA, Stampfer MJ, Willett WC \& Hu FB (2004) Sugar-sweetened beverages, weight gain, and incidence of type 2 diabetes in young and middle-aged women. JAMA 292, 927-934.

Srinath Reddy K \& Katan MB (2004) Diet, nutrition and the prevention of hypertension and cardiovascular diseases. Public Health Nutr 7, 167-186.

Steffen LM \& Jacobs DR Jr (2003) Relation between dairy food intake and plasma lipid levels: the CARDIA Study. Aust J Dairy Technol 58, 92-97.

Steffen LM, Jacobs DR, Stevens J, Shahar E, Carithers T \& Folsom AR (2003) Associations of whole grain, refined grain, and fruit and vegetable consumption with all-cause mortality, incident coronary heart disease and ischemic stroke: The ARIC Study. Am J Clin Nutr 78, 383-390.

Steffen LM, Kroenke CH, Yu X, Pereira MA, Slattery ML, Van Horn L, Gross MD \& Jacobs DR (2005) Associations of plant foods, dairy products, and meat consumption with fifteen-year incidence of elevated blood pressure in young black and white adults: the CARDIA study. Am J Clin Nutr 82, 1169-1177.

Thelle DS, Arnesen E \& Forde OH (1983) The Tromso heart study. Does coffee raise serum cholesterol? N Engl J Med 308, 1454-1457.

van Dam RM \& Hu FB (2005) Coffee consumption and risk of type 2 diabetes: a systematic review. JAMA 294, 97-104.

Yli-Jama P, Haugen TS, Rebnord HM, Ringstad J \& Pedersen JI (2001) Selective mobilisation of fatty acids from human adipose tissue. Eur J Intern Med 12, 107-115.

Yli-Jama P, Meyer HE, Ringstad J \& Pedersen JI (2002) Serum free fatty acid pattern and risk of myocardial infarction: a case-control study. J Intern Med 251, 19-28.

Zock PL, Katan MB, Merkus MP, van Dusseldorp M \& Harryvan JL (1990) Effect of a lipid-rich fraction from boiled coffee on serum cholesterol. Lancet 335, 1235-1237. 